G. Becciu, et al., Int. J. Sus. Dev. Plann. Vol. 15, No. 1 (2020) 81-94

\title{
MANAGEMENT OF WATER AND WASTEWATER UNDER THE FRAMEWORK OF THE IMM: THE CASE OF THE FAVELA ROCINHA
}

\author{
GIANFRANCO BECCIU ${ }^{1}$, STEFANO MAMBRETTI $^{1,2}$, GABRIELE MASERA $^{3}$, \\ UMBERTO SANFILIPPO ${ }^{1} \&$ MASSIMO TADI ${ }^{3}$ \\ ${ }^{1}$ DICA Politecnico di Milano. \\ ${ }^{2}$ Wessex Institute of Technology. \\ ${ }^{3}$ Dept. ABC Politecnico di Milano.
}

\begin{abstract}
The paper presents the so-called Integrated Modification Methodology (IMM), which is aimed to make cities and human settlements more inclusive, resilient and sustainable. In particular, the paper resumes how it has been implemented to the case study of Favela Rocinha in Rio de Janeiro. IMM is the result of a research project financed by Politecnico di Milano university using Italian national funds allocated by law to social purposes. This kind of projects have to be multidisciplinary and in favour of human and social development. Many are the aspects considered in the project case study: energy, work, mobility, ecosystem, service, food and waste water). For all of these aspects, which are crucial in Rio de Janeiro slums, the engineering issues have to be matched not only with the requests of the other practitioners working on the same area, in a holistic view of the problems, but also with cultural and social constraints. The aim of this approach is to produce integrated solutions which can be understood by the population, made its own and so managed in the best possible way; so, the cultural improvement may also produce a relevant economic activity. In the paper, the methodology for approaching a difficult case like Favela Rocinha is presented, together with the main outcomes of the work of the different specialists who dealt with the different parts of the work. In details, the paper deals specifically with water and wastewater management, to show more deeply the applied methodology. The paper shows that this approach has requested, in some cases, to propose solutions that textbooks would not consider theoretically the 'best' ones, but that are more suitable for the actual situation of a slum like Favela Rocinha, definitively to make the development of those systems more inclusive, resilient and sustainable.

Keywords: community involvement in urban modifications, urban management, water and wastewater management.
\end{abstract}

\section{INTRODUCTION}

Universities are the highest level teaching centres in the developed societies, and they also are institutions that produce scientific development, certified by published papers. Besides these activities, it is not so common the social involvement of faculties and staff in coordinated and stimulated actions. Since 2006, the Italian government allocates a portion of national tax revenue, equal to $0.5 \%$ percent, to support activities of registered non-profit organizations for projects with social goals. Each taxpayer may choose which organization will be supported with his/her/its taxes.

The share of this fund that Politecnico di Milano (Italy) receives annually, as it is a university committed also in social projects, is used to support the best social projects submitted by its own faculties, also involving other non-profit institutions and organizations. The choice is done by a competitive selection called 'PoliSocial Award'. The aim is to promote and encourage new multidisciplinary approaches attentive to human and social development, expanding training opportunities and research offered to students, researchers, and the university teaching and technical-administrative staff.

The project PoliMiParaRocinha was launched and developed within the initiative of PoliSocial Award in 2017, in partnership with 'Il Sorriso dei Miei Bimbi' (a non-profit 
organization engaged with the community of Rocinha favela in Rio de Janeiro, Brazil), to support the development of an urban management system (UMS) able to manage and integrate several urban data and services. Favela is a Brazilian Portuguese word for slum, a low-income historically informal urban area in Brazil.

As favelas are associated with poverty and illegality, residents of favelas are often discriminated against for living in these communities and often experience inequality and exploitation; this kind of stigma, that is associated with people living in favelas, can lead to difficulty in finding jobs [1] and to be accepted in the other urban contexts. Moreover, aggressive eradication policies characterised state-sanctioned interventions, even with the creation, in 1979, of the BOPE (Batalhão de Operações Policiais Especiais - Special Police Operations Battalion), the police tactical unit of the Military Police of Rio de Janeiro State.

In the last years, although aggressive interventions did not disappear, the Government has realized the importance of initiatives that combine public security with intra-favela initiatives. The project PoliMiParaRocinha aims to contribute in this direction.

The paper presents the case study and the approach used for developing an integrated project in a difficult environment. As the approach is holistic and aims to consider all the different aspects to improve the life of the inhabitants of the area, the paper - although briefly covering the different topics - deals specifically with water and wastewater management, in order to show more in-deep how the method is applied.

In Section 2 the case study of favela Rocinha is described and the main references about the implemented methodologies are provided; Section 3 briefly covers the core issues faced by this project, while Section 4 provides a focus on water management.

\section{MATERIALS AND METHODS}

Rocinha is the largest and most populous favela in Brazil, located in Rio de Janeiro's South Zone, on a steep hillside, about one kilometre from a nearby beach (Fig. 1). Almost all the houses in Rocinha are made from concrete and bricks. Some buildings are three and four storeys tall and almost all houses have basic sanitation, water supply infrastructure and electricity; compared to simple shanty towns or slums, Rocinha has a better developed infrastructure and hundreds of business activities services such as banks, shops (including even medicine stores), bus routes, cable television (Fig. 2). However, being an informal and unstructured development, it suffers from several interlaced problems: uncollected waste in

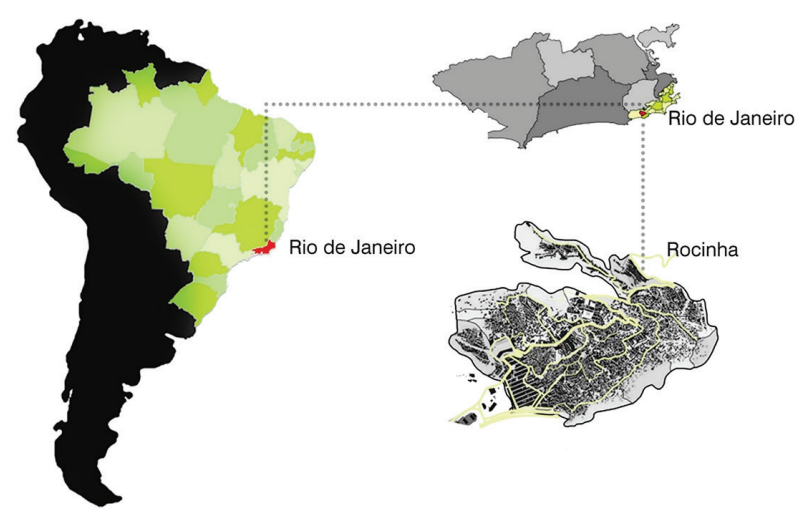

Figure 1: Localisation of the favela Rocinha. 


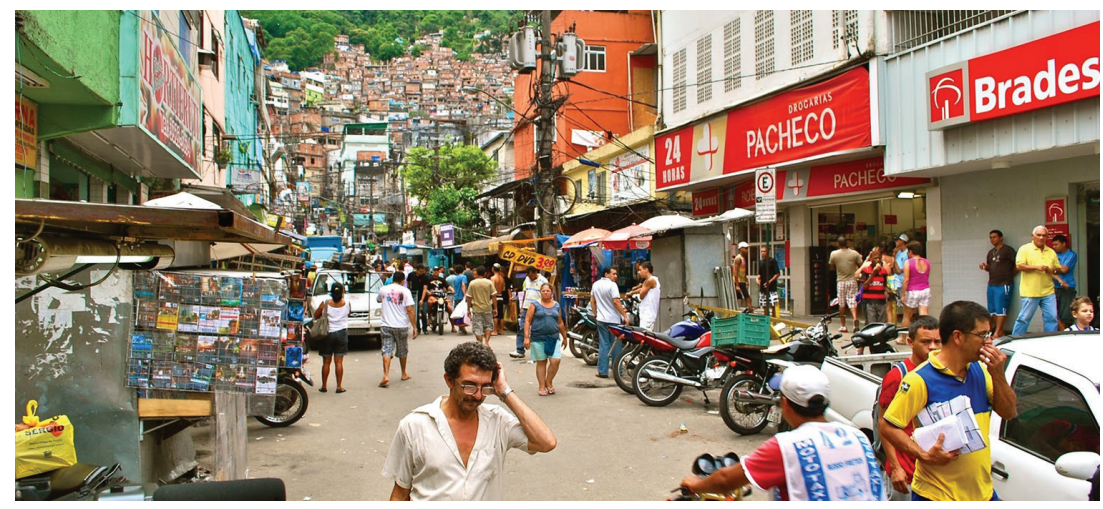

Figure 2: Life in the favela Rocinha.

the streets, limited access to healthy food and clean water, nonexistence of an effective system to collect and treat wastewater, and an ineffective mobility system are among the basic issues.

Within the PoliMiParaRocinha project all the data available from public sources were collected, in order to evaluate the amount of waste generated in Rocinha, and its composition. Existing data are mostly based on information provided by the Municipality of Rio de Janeiro, but other sources were available as well. When possible, complete data series were used for the analysis $[2,3,4,5]$. However, most of data had to be verified. For instance, the number of inhabitants were estimated in about 70'000 by a survey carried out in 2010 [3], while informal (and more reliable) estimations by local experts give figures around 200,000.

Working on an interconnected set of problems, requires an interconnected system of solutions. The theoretical background of the project is the Integrated Modification Methodology (IMM) [6], a scientific intervention method developed at Politecnico di Milano university. IMM is a methodological interpretation of the UN's Sustainable Development Goal number 11 [7], which is one of the 17 goals identified within this framework; it is entirely about cities and human settlements to be made inclusive, resilient and sustainable.

Regardless of its size, any urban area can be considered as a Complex Adaptive System, under the point of view of a IMM. On the basis of the mutual systemic relations which characterize the Rocinha, investigated by the project in a multiscale manner, some improvement scenarios, specific for the context under study, will be developed. In fact, a Complex Adaptive System (CAS) is a particular scheme of a complex system with the ability to learn from prior experiences. The elements of the System are supposed to be able to adapt themselves to improve their performance, in response to new internal and external constraints. So, the IMM simulation methodology, based on a series of CAS analyses, offers a powerful tool to propel the urban transformation towards achievable goals.

Generally speaking, IMM is a design methodology developed to improve the performance of the CAS; the main characteristics of the IMM are based on three fundamental approaches: (i) holistic, (ii) multi-layer and (iii) multi-scale.

Due to the fact that the success of the project emerges from actions coming from heterogeneous elements (drivers and constraints), the project should deal with its own complexity in a holistic way. Dealing with complexity prompts every researcher to face with convoluted difficulties; so there is the risk that any approach based on too much simplified hypotheses 
will cause unrealistic results: therefore, it is necessary to refer to field studies and to avoid reductionist (top-down) investigation.

The multi-layer analysis of IMM could be achieved by means of the involvement of different experts in different disciplines. In terms of sustainability, for instance, the environmental layer has to be implemented integrating it with the social and the economic layers.

The modification of the elements of the CAS which will cause the final transformation of the system may occur in different scales. Similarly, the urban interventions operate on different scales. As the modifications of CAS are classified in minor (local), medium (intermediate) and major (global) scale, any intervention effect has to be considered in each one of these three mentioned scales. In particular, the intermediate interventions bridge the gap between minor and major scales. So, the designers should concentrate their efforts on the fixed operational area, i.e. the medium scale, but they have also to deal with the related minor (local) scale and the major (global) transformation. Accordingly, in the IMM process, the designers have to specify the intermediate scale as a fixed area of intervention, i.e. the borders of their intervention area, but - at the same time - this area has to be seen as a part of a single entity.

\section{COVERED TOPICS}

Based on the described multidisciplinary and integrated design methodology, the project foresees several focus studies on different topics for the sustainable regeneration of Rocinha. The different aspects that have been investigated are:

- Energy;

- Waste;

- Mobility;

- Ecosystem services;

- Food;

- Water and wastewater management.

To effectively tackle these issues, it is necessary to target the urban context first, create a flexible connected system and-then-define sub-local strategies to improve the situations related to the urban life. To activate this systemic reaction, three areas inside the favela Rocinha have been selected to implement the project, extrapolating the achieved results to the entire favela through a multiscale approach.

\subsection{Energy}

The energy project aims to fulfil basic electric power needs of the low-income households of the favela, increasing the availability of energy. In Rocinha the solar radiation is high and the sky cover is low along the whole year [8]. Then, there is abundance of solar radiation at the ground level and especially on rooftops, exploitable through photovoltaic (PV) systems installing panels on the rooftop of the buildings. Solar energy exploitation can, in this way, reduce electricity thefts and increase grid reliability inside the favela. To maximize energy self-consumption, especially during nights, PV panels have to be coupled with battery energy storage systems.

With regards to the potentiality of this energy source, the maximum registered value of yearly global horizontal radiation is about $1850 \mathrm{kWh} / \mathrm{m}^{2} /$ year and, on average, the solar potentiality of the majority of the roofs is about $1760 \mathrm{kWh} / \mathrm{m}^{2} /$ year. Considering solar polycrystalline panels as $14 \%$ efficient (that is a precautionary estimation), with a module surface of $1.7 \mathrm{~m}^{2}$ and a nominal power of $230 \mathrm{~W}$, each PV panel can produce up to $315 \mathrm{kWh} /$ panel/ 
year if it is installed horizontal, and $337 \mathrm{kWh} /$ panel/year, if it is installed with a tilt angle of $25^{\circ}$ (which is the optimal value for the latitude of Rocinha). The panels can be installed on the roofs: so, the usable area can be considered equal to the entire surface if the roof is not walkable or equal to just a part of the surface, i.e. $46 \%$ in the Rocinha case study, if the roof is walkable.

Overall, and considering different options of installation and roof availability, the total maximum potential production has been estimated to be in the range $900,000 \mathrm{kWh} / \mathrm{year}-$ 1,950,000 kWh/year. Rocinha's residential energy use could be represented between 1,800-3,000 kWh/house/year [9]. Therefore, considering an average electrical energy consumption of $200 \mathrm{kWh} /$ household/month (2,400 kWh/household/year), and having estimated 951 apartments in the selected area, the total electricity needs of the selected residential buildings is around 2,280,000 $\mathrm{kWh} /$ year. As already mentioned, the electric power battery storage, if properly done, can maximize the energy self-consumption of the electric power energy produced on site by PV panels, minimizing the interaction with the national grid and the need for further strengthening of the local energy network. Nevertheless, batteries and biogas may be too expensive. So a cost / benefit analysis about them is required as a further development of the project.

\subsection{Waste}

In Rocinha, streets are narrow and the lack of space is a significant constraint in waste management procedures. The collection stage is performed by a municipal enterprise, but waste collection points are not enough and sometimes they are not even accessible, because of their location along the most congested roads [10]. Moreover, the frequency of the collection is not sufficient, and this fact is the main cause for both the spreading of the waste in the surrounding of collection points and the illegal disposal (Fig. 3). The magnitude of the problem is fully understandable just considering that improper disposed waste is estimated to be about $41 \%$ of household waste $(0.59 \mathrm{~kg} / \mathrm{hab} / \mathrm{d}$ out of $0.78 \mathrm{~kg} / \mathrm{hab} /$ day of average waste production per capita).

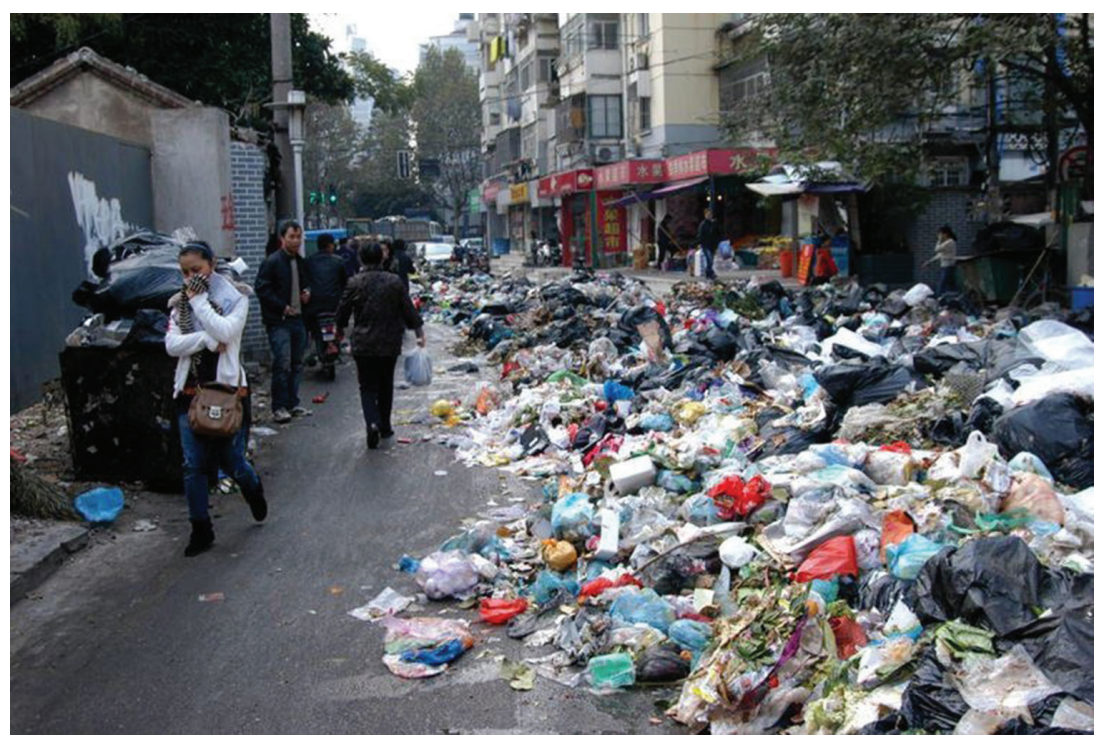

Figure 3: Waste disposal in the Rocinha. 
When approaching waste management problems, all the process stages should be taken into account, from the production to the final disposal, going through collection and treatment. However, the focus of this study is Rocinha, and what happens after the collection waste is moved out of Rocinha, entering the larger system of Rio de Janeiro, is outside the scope of the project. Consequently, the proposed strategy focuses on waste production, primary collection and storage, including small-scale treatments when possible. This strategy consists in a parallel collection system with the purpose of diverting valuable materials from the general collection. This would lead to two positive big results: recovery and recycling become a source of income, and the existing collection system is less congested and easier to manage. The parallel collection system is going to work through cooperatives, following an existing model of the collectors of waste (catadores de lixo) who select recyclable materials for subsequent trade.

An analysis was done for the six zones identified within the project area. A first result was the calculation of the amounts of waste produced in each area. This information was subsequently used to calculate the area needed for storage, the number of bins necessaries for the implementation of separate collection and their location along the street network. The establishment of a node of the collection network in each zone is expected to partially intercept the waste produced by $11 \%$ (that is about 24,000 inhabitants) of the population of Rocinha, leading to the diversion of 4 tons of organic waste and 3 tons of recyclables each day.

Small-scale treatments, such as the production of biogas for a public facility (like the canteen of a school), respecting safety criteria, requires a minimum basin of population to be involved, but this possibility has not yet been defined.

\subsection{Mobility}

Despite the presence of São Conrado Metro Station on the eastern part of the favela, the current mobility system of Rocinha present critical issues, which affect the life of the community. Most of the streets are narrow (in a stifling way) and the topography is erratic; inside the favela itself, public transports are at a minimum level, as only one bus lane covering just few areas where streets are larger.

The mobility objective in the project is to create an affordable and integrated bike sharing system which activates the internal connections and assists the existing public transportation infrastructure. According to width and slope standards, the street structure has been analysed and an optimum joined network created by streets which are qualified for conveying bicycles traffic was selected. In particular, the analysis showed that 13 in 18 subareas have favourable morphological characteristics while the others 5 areas can't be accessible by bikes due to the high ground slope.

The analysis of the favela's population has allowed to estimate the potential of the system, where already $17,63 \%$ of the residents are bicycle owners. The daily trip per person, introducing the mobility index value, that permits to calculate the average of daily trip made by a single person, has been considered to estimate the dimension of the bike sharing system. Based on that, the estimated dimension of new bike sharing system is of 180 electric bikes, distributed in 12 bike stations each of them with a max capacity of 30 bicycles. The system is linked to the Urban Management System; and therefore, the electric bikes could be charged by the locally produced energy.

\subsection{Ecosystem services}

Ecosystem Services (ES) are defined as 'the benefits derived by humans from the properties and processes of ecosystems (e.g. food production and waste treatment)' [11, p. 2] or as 
'natural capital stocks (including ecosystems and biodiversity) ... which contribute to human well-being at all levels' [12, p. 69]. Therefore, ES assessment was applied with the aim to estimate environmental condition considering that urban liveability is influenced by the natural environment (e.g. soil, air and water). In this context, it has to be observed that the conditions of informal settlements and the low-cost construction materials bring to high vulnerability of the structures and of their inhabitants, increasing the risk level related to natural disasters such as landslides or flooding.

At supra-local scale, two ES assessment were carried: (1) habitat quality, as a supporting service which is an essential indicator of local environmental quality and biodiversity; (2) carbon sequestration for climate regulation. Besides, an analysis was conducted at local level considering the upstream runoff processes that could affect the hydro morphological stability conditions of the favela.

Based on the multiscale ES mapping (supra-local and local), some critical areas have been identified to improve territorial resilience and to define possible Nature-Based Solutions as actions addressing ecological, social and economic challenges. The ES mapping and assessment has been recognized in the project as the pivotal activity to establish appropriate actions to foster system resilience.

\subsection{Food}

The problem of healthy nutrition is serious for most of the inhabitants for the lack of both fresh food and education. To improve the quality of nutrition, people involvement has been considered crucial, and therefore it has been proposed to introduce a synergic strategy toward a new circular metabolism of the favela's internal processes. Because of the almost total absence of voids in the area (Fig. 4) and its high slope, pursuing some kind of traditional cultivations was considered impossible; therefore, the project has been oriented towards

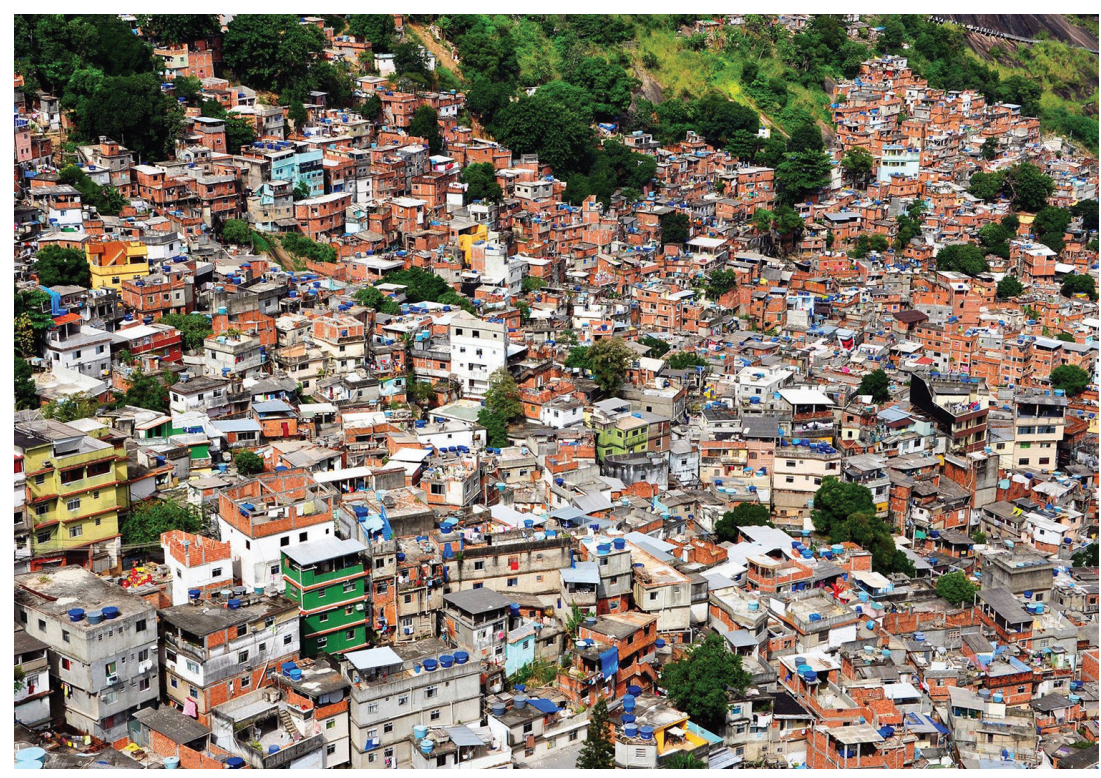

Figure 4: Aerial view of a part of the favela Rocinha. 
innovative and sustainable strategies of urban agriculture, integrated with existing buildings, like green roofs, vertical farming and aquaponics.

The vegetable gardens raised by the local communities can provide fresh fruits and vegetables, with the goal to increase the offer of fresh food and to educate children on healthy food. Aquaponics greenhouses, producing fishes and vegetables, participate to the local food strategy production and simultaneously aim to foster local economies. In addition, a vegetated garden system is very important also from the point of view of reducing the rainfall runoff from the favela impermeable surfaces, responsible of flood damages during heavy rainfall events. This is the reason why the food topic has been considered with a strong correlation with the water management sector and the waste management, especially with the re-use of organic waste.

\section{WATER AND WASTWATER MANAGEMENT}

\subsection{Wastewater management}

In order to protect public health, construction and proper maintenance of appropriate infrastructural works and non-structural measures to manage water and wastewater are critical. At the moment, neither waste waters nor rainfall waters are collected in favela Rocinha, and they just flow inside the 'canals' between the houses, following the directions of greater slope (Fig. 5).

In this case, problems to be faced are not only related to technical difficulties (e.g. the high slope of the area), but also social and educational, being clear the lack of education or culture related to the health issues for so many people living in a deteriorated environment and the possible, consequent, misuse of the designed constructions and the resultant troubles in their management.

The construction of separate sewerage networks, in order to follow Brazil's own design standard, has been proposed. Moreover, in order to allow the start of an economic activity, although minimal, all the related procedures should be standardized; this implies that they must be simplified. As mentioned in the Section 2, first step has been the identification of an area that can act as a 'pilot', in order to set up and check procedures that later can be replicated in other similar areas. In this sense, for instance, it has also been considered the placement of standardized pipes and canals, which can be easily calculated on the basis of specific guidelines.

Supplied drinking water, a part of which must be collected after use, comes from tanks of the local public aqueduct. Generally speaking, only about $80 \%$ of water used for residential needs is transformed in foul water and then it has to be collected by a sewerage system. It is therefore quite easy to compute the foul flow rates in sewage pipes and canals, from the per capita average water supply consumption, and to develop standard simple design procedures.

In this project, it has also been considered the possibility of increasing water availability by supporting the rainwater harvesting from roofs. This water must be collected in tanks and, in principle, could be used only for non-drinking purposes, unless a proper treatment system is implemented. Therefore, the overall volume of wastewaters to be collected by the sewerage system has been supposed to be higher than the one due to just the aqueduct distribution.

From the point of view of hydraulic engineering, the project is quite easy to be carried out, consisting in the division of the area into appropriate sub-basins, in which the number of inhabitants are estimated to compute the wastewater flows. First, in order to achieve 


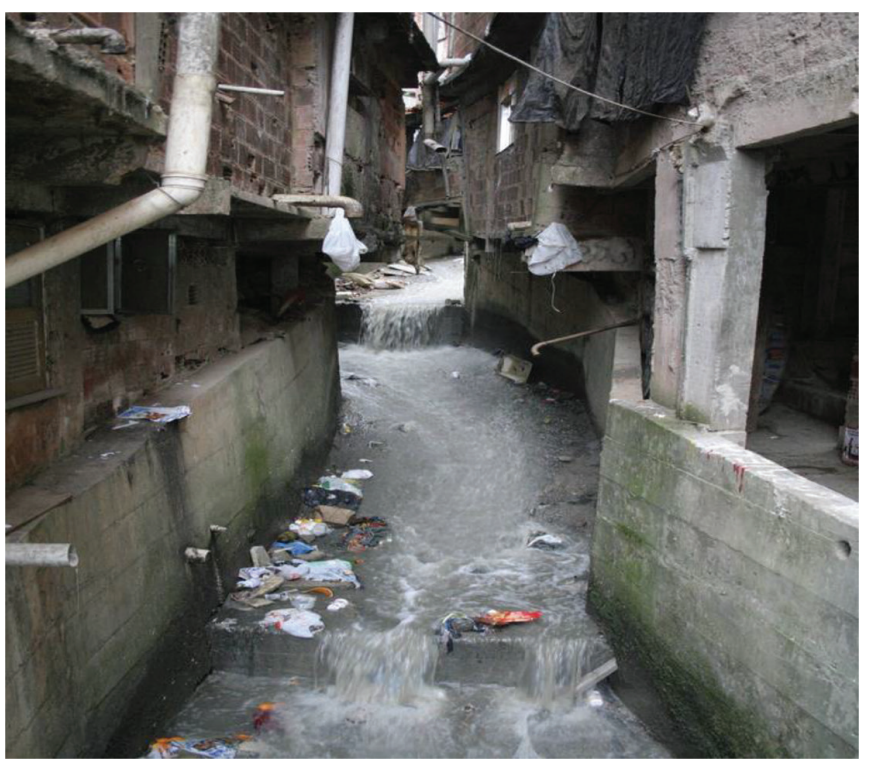

Figure 5: Open canals between the houses.

prudential reference values, an average of 150 litres/(person day) of water consumption has been considered. This value is referred not only to the daily average and the annual peak of water supplied by the water distribution system, but also, as mentioned, to possible contribution of harvested rainwater and also of a possible component of stormwater entering in the sewerage system.

On the base of the topography of the area, the positions of the main pipes have been traced and their design dimensions calculated. Considering the complexity of this specific urban context in comparison with usual urban areas, the pipes must be easy to move, install, remove and inspect, and they must be protected from damages, impacts, and sunlight. The outfall of the developed network should be a treatment plant, in order to reduce the impact of wastewater discharge in the environment.

The selected area is quite small (Fig. 6) and it has been divided in 4 subareas with the following characteristics:

- AA: 4 buildings, 79 inhabitants;

- BB: 22 buildings, 435 inhabitants;

- CC: 39 buildings, 772 inhabitants;

- DD (complete area): 48 buildings and 950 inhabitants.

The main concerns have been the significant slopes and the consequent potential high water velocities. Normally, this means that there is the need of a number of drops in the pipelines, which can also be used for inspection and removal of sediments and other materials transported by water or introduced as garbage. In this case, however, this option was judged inappropriate and therefore discarded, due to the costs and the technical difficulties of creating an underground piping system in Rocinha. So, it has been decided to avoid digging, just 


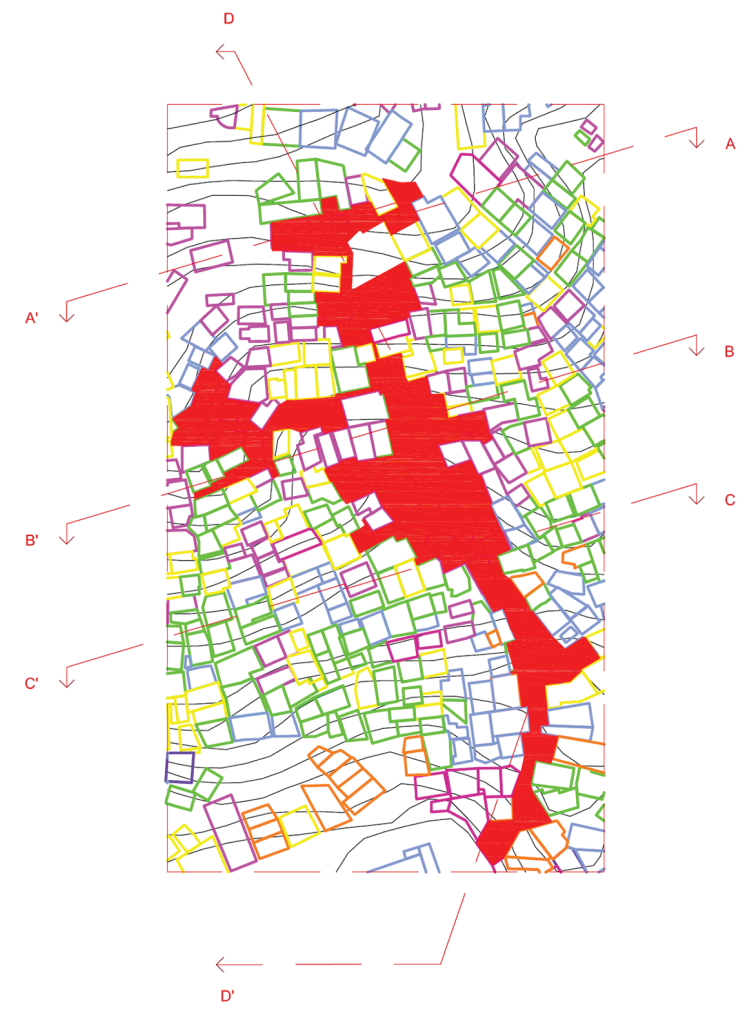

Figure 6: Pilot area for the design of the sewerage system.

laying pipes on street sidewalks, if present, or on a side of the passage between buildings, therefore accepting potential high water velocities inside them. Small drops have been considered only when velocities exceed $5 \mathrm{~m} / \mathrm{s}$. It has to be highlighted that, in the most upstream pipes, low flows could cause water velocities to be too low to avoid sedimentation of suspended solids. In these cases, it is possible to send part of stormwater flow from roofs into the pipes in order to have an occasional washing during storms.

\subsection{Stormwater collection}

It is worth mentioning the importance of proper management of stormwater, which is essential to ensure the safety of the territory. In general, in small and steep catchments, sudden flooding events, called flash floods, are common. Although the hydrological processes involved in the transformation of intense rainfall into runoff are well-known, these phenomena are dangerous because of their rapidity and the difficulty of forecasting in advance. This is even more true in areas where urbanization is the result of unplanned, self-organized processes, as in Rocinha. In this kind of contexts, dominated by impervious surfaces and with inadequate drainage structures, the runoff is mainly conveyed by streets. In most cases, the absence of street gutters and even of sidewalks, combined with high street slopes, makes walking or moving by bikes or other kind of transportation dangerous for people during flood events [13]. Quality issues related to stormwater are also critical. Surface runoff during 
rainstorms has a significant rate of solid matter, harvested by water flows. This component is due to wooden debris and soil erosion in the vegetated slopes surrounding the urban area, to garbage and other solid wastes left on streets, to degradation of buildings materials, to hydrocarbons and other fluids related to cars and motorcycles. The solid fraction of stormwater runoff is highly polluted and represents a source of hazard for people health and has also a dangerous impact on downstream receiving water bodies.

Rocinha is built in the valley below the Two Brothers Mountain, covering part of the mountain slopes. These slopes are steep and vegetated, mainly by trees. Although rainfall is mostly intercepted by vegetation and infiltrated in pervious soils during mild precipitations, surface runoff is produced during more intense rainfall events. Water flows enter the urban area both by overland flow and by a networks of brooks converging to the valley bottom. Some segments of original brooks have disappeared, because they had been progressively incorporated and absorbed in the urban tissue. On the other hand, some of brook segments have been transformed in 'artificial' open channels that convey water to a main channel outflowing downstream to the sea. These drainage network is insufficient in most cases and runoff often causes the flooding of streets and houses.

To achieve a proper stormwater management, reducing the risk of flooding, it is essential to limit the external component of runoff as much as possible. This aim can be achieved by building open channels along the borders of urbanized area, collecting water from the vegetated area outside and discharging it entirely downstream of the urban area, in the existing main drainage channel. Two channels of this type already exist, partially protecting the urban area, but it is necessary to extend and connect them. The design of these channels has to take into account both the risk of bed erosion and the risk of flooding. About the first issue, the channel bed is to be built with suitable material (e.g. geotextiles, concrete or stone masonry, etc.). In steepest segments, drop structures have to be built to reduce channel slope and to limit water velocity.

The second issue is more complex. Taking for granted that is virtually impossible to reduce the flooding risk to zero, due to the random nature of rainstorms, the focus should be addressed to damage reduction. This result can be achieved, in the Rocinha case study, constructing channel banks of different heights and providing 'controlled' flooding areas along the channels on the vegetated side, that is on the opposite side of the urban area, in order to attenuate flood peaks. The design has been based on a 10-years return period rainstorm for the channel conveyance and on a 50-years return period for the controlled flood attenuation areas.

In order to properly design this urban drainage infrastructure, a map of the areas subject to this risk $[14,15]$ is needed. This activity has been developed on the basis of both the analysis of the available historical data and the hydrological and hydraulic modelling of the area with its natural and artificial drainage networks. As far as historical data concerned have been required, a document research has been carried out, and their storage in an appropriate multimedia database planned, in order to facilitate their future use. Of course, this database will have to be updated with respect to the new needs, thus including, in addition to numerical data, the mapping of the area and, where available, adequate photographic and filmographic documentation. For hydrological-hydraulic modelling, simple and robust procedures are used. It should be highlighted that the calculations applied to the catchment, mainly based on the Rational Method can be considered sufficient just for a first evaluation, but they may be strongly improved with the aid of computer programs running distributed and physically based models which allow a much higher accuracy. 
In addition to the database creation and the risk map preparation, a study has been set up about the traditional practices for the management and care of this specific territory. This study, still not yet completed, is aimed to the verification of the traditional practices in light of the latest advances in naturalistic engineering, to offer innovative suggestions to the methods usually applied to protect the territory. For this purpose, a training course will be carried out involving cultural mediators who have the function of working with communities in order to involve them in responsible management.

The final results of the project, in addition to the improvement of the safety of the area when it will be completed the final part of the by-pass to collect stormwater, will also be $(i)$ the creation of a system for mapping of hazardous areas and (ii) the archiving of spatial data in the form of multimedia. Moreover, the fostering of a new knowledge, geared to the traditional one and addressed to rural communities, can be achieved.

These outcomes are coherent with the general concept that both structural and non-structural measures have to be taken to properly deal with risk [16]. The knowledge of areas under risk and the community awareness can be considered the first fundamental step of all the possible interventions aimed to reduce the vulnerability of the populations. To achieve this goal, in other words, the key point is that not only the territory must be subject to a better risk management, with proper structural and non-structural measures but also the communities must become aware and prepared to deal with risk situations, even including those due to climate change. Of course, to improve the preparedness of the community and in order to allow an effective early warning system, an adequate network of survey instruments (raingauges, flowmeters, level meters, and so on) have to be positioned and maintained in the catchment.

\subsection{Community involvement and project sharing processes}

It is essential to emphasize the need of a direct involvement of the communities, also to ensure the proper use of the drainage network (for example: no solid wastes, even crushed, have to be discharged in the pipes) and for the best territory management. Researches (see e.g. $[17,18])$ have clearly shown that community participation and community-based management are crucial themes in current policy, especially those dealing with natural resources management.

Such 'holistic' form of people's participation is required for area-based operations which affect all inhabitants like environmental protection, soil and water conservation, provision of physical, economic and social infrastructures and irrigation, sanitation and health schemes. Moreover, according to Agenda 21, one of the most important points to make environmental policies more focused on communities is the participatory approach and public participation, including women, children, indigenous peoples and farmers [19].

In addition, the involvement of the community in the project development can ensure, on one hand, deeper awareness and interest in the work and, on the other hand, skills training that can be used to learn the proper construction and management of sewage networks, which can generate an economic activity. As for the land management and risk awareness, skills in this field might be also developed, with special attention to basin reclamation and involving also naturalistic engineering and plant nurseries, which is, again, a possible generation of a positive increase of the economic activities.

Activities with the participation of the local population to the Rocinha project have been made possible by the help of the Italian NGO 'Il sorriso dei miei bimbi' ('My children's smile'), which has been working for more than 18 years in the favela Rocinha, and 
the personal efforts of its operators, who know very well the dynamics and the policies of this community.

\section{CONCLUSIONS}

The paper presents the Integrated Modification Methodology, developed at Politecnico di Milano, which is aimed to make cities and human settlements more inclusive, resilient and sustainable. In particular, the paper resumes how it has been implemented to the case study of favela Rocinha in Rio de Janeiro.

Favelas are slums, low-income and informal urban areas in Brazil, which have been historically subject to an unplanned development leading to a series of interconnected problems, impossible to solve if not applying an integrated methodology which works considering holistically all the different involved topics.

As the Italian government addresses 0.5 percent of citizens' taxes to institutions carrying out social activities, Politecnico di Milano annually announces a competition for activities supporting developing Countries. The hereby presented project called PoliMiParaRocinha, has been funded in 2017, in the framework of a call of the PoliSocial Award using the portion of that 0.5 percent assigned to Politecnico di Milano.

As the aspects to be improved in the favela Rocinha are so many, Section 3 briefly presents the topics covered by the project, while Section 4 shows more in-deep details of the part of the project related to water and wastewater management. It has been shown as the different aspects are all interconnected, and developing the project the theoretical 'best engineering practice' has to be slightly modified in order to meet the requests coming from the communities. In fact, it is essential to involve the local communities in the urban modifications, to create a new awareness that in turn allows a better management of the structures and the environment and that, eventually, may produce also interesting economic activities tied to the cultural improvement.

\section{REFERENCES}

[1] Ribeiro, D., O Povo Brasileiro Companhia das Letras, São Paulo (in Portouguese), 1995.

[2] IPP-Institute Pereira Pasos, Armazém de Dados, Prefeitura de Rio de Janeiro (in Portouguese) http://www.data.rio/, 2017.

[3] IBGE_-Instituto Brasileiro de Geografia e Estatística, (in Portouguese) https://www. ibge.gov.br/, 2017

[4] SNIS - Sistema Nacional de Informações sobre Saneamento, Ministério das Cidades (in Portouguese), http://www.snis.gov.br/, 2017.

[5] EMOP - Empresa de Obras Públicas. Relatório de Diagnóstico Urbano, Ambiental e Social, Estado do Rio do Janeiro (in Portouguese), 2012.

[6] Tadi, M. \& Manesh, S.V., Transformation of an urban complex system into a more sustainable form via Integrated Modification Methodology (IMM). International Journal of Sustainable Development and Planning, 9(4), pp. 514-537, 2014. https:// doi.org/10.2495/sdp-v9-n4-514-537

[7] UN DESA, The Sustainable Development Goals Report 2017, United Nations Department of Economic and Social Affairs, New York, NY, https://doi.org/10.18356/4d038e 1e-en, 2017.

[8] Arcidiacono, A., Causone, F., Grosso, M., Masera, G., Tadi, M. \& Zadeh, H.M., Environmental performance and social inclusion: A project for the rocinha favela in 
Rio de Janeiro. Energy Procedia, 134, pp. 356-365, 2017. https://doi.org/10.1016/j. egypro.2017.09.546

[9] World Energy Council, Measures for low-income households. London: World Energy Council. https://www.wec-policies.enerdata.eu/Documents/cases-studies/Measuresfor-low-income households.pdf, 2010.

[10] Carvalho, M.I. \& Bastos, V.P., A favela da Rocinha e a destinação inadequada de lixo: entendendo os meandros da questão, Master Thesis in Social Service, Pontifícia Universidade Católica do Rio de Janeiro, 2016

[11] de Groot, R., Wilson, M. \& Boumans, R.M.J., A typology for the classification, description and valuation of ecosystem functions, goods and services. Ecological Economics, 41, pp. 393-408, 2002. https://doi.org/10.1016/S0921-8009(02)00089-7

[12] TEEB, The Economics of Ecosystems and Biodiversity in National and International Policy Making. ed. P. ten Brink. Earthscan, London and Washington, 2011.

[13] Bignami D.F., Rosso, R. \& Sanfilippo, U., Flood Proofing in Urban Areas, Springer Nature, Switzerland, 2019. ISBN 978-3-030-05933-0, https://doi.org/10.1007/978-3030-05934-7

[14] van Duivendijk, J., Manual on Planning of Structural Approaches to Flood Management. ICID Guideline, New Delhi, India, 2005.

[15] Einstein, H.H., Special lecture: Landslide risk assessment procedure. In International Symposium on Landslides. Landslide, ed. C. Bonnard. Vol. 2, Lausanne, pp. 1075-1090, 1988.

[16] De Wrachien, D., Mambretti, S. \& Schultz, B., Flood management and risk assessment in flood-prone areas: Measures and solutions. Irrigation and Drainage, 60(2), pp. 229-240, 2011. https://doi.org/10.1002/ird.557

[17] Chirenje, L.I., Giliba, R.A. \& Musamba, E.B., .Local communities' participation in decision-making processes through planning and budgeting in African countries. Chinese Journal of Population Resources and Environment, 11(1), pp. 10-16, 2013. https://doi.org/10.1080/10042857.2013.777198

[18] Abbott, J., Community participation and its relationship to community development. Community Development Journal, 30(2), pp. 158-168, 1995. https://doi.org/10.1093/ $\operatorname{cdj} / 30.2 .158$

[19] Eden, S., Public participation in environmental policy: considering scientific, counterscientific and non-scientific contributions. Public Understanding of Science, 5(3), pp. 183-204, 1996. https://doi.org/10.1088/0963-6625/5/3/001 